\title{
Complementary and Alternative Medicine in Cardiovascular Care
}

\author{
AKMM Islam ${ }^{1}$, MT Rahman ${ }^{1}$, M Ahmed $^{1}$, MAU Chowdhury ${ }^{1}$, A Khair $^{1}$, M Ullah $^{1}$, L Yeasmin $^{2}$ \\ ${ }^{1}$ Department of Cardiology, National Institute of Cardiovascular Diseases, Dhaka, ${ }^{2}$ Department of \\ Chemistry of Dental Materials, Dhaka Dental College, Dhaka
}

Key words:
Complementary
and alternative
medicine,
Herbals,
Cardiovascular
care.

\begin{abstract}
Complementary and alternative medicine (CAM) refers to a broad set of health care practices that are not part of a country's own tradition and are not integrated into the dominant health care system. Herbal remedies, dietary supplements, acupuncture, homeopathy, ayurveda, unani, traditional Chinese medicine, prayer, yoga and meditation are the common examples. CAM therapies often represent an enormous area of unregulated and widely practised therapeutics with an inadequate scientific literature. However, there is emerging evidence that some of the CAM therapies are effective in certain clinical conditions. Presently, throughout the world, there is rampant growth of CAM industries, and increasing number of reputed pharmaceutical companies are producing herbals and dietary supplements. Herbal products used for cardiovascular purposes include garlic, hawthorn, ginkgo, horse chestnut and arjun. These substances are often popularly believed to be 'natural', hence safe. But adverse reactions including deaths have been reported with some of the CAM products. There is also growing concern for significant drug interaction among commonly used herbals, dietary supplements and cardiovascular drugs. At present, CAM therapies may best be regarded as an adjunct to standard medical care. More scientific research and strict regulation by standard national and international authorities are needed to ensure their efficacy and safety in cardiovascular care.
\end{abstract}

(CVJ 2008; 1(1) : 84-96)

\section{Introduction}

Complementary and alternative medicine is a group of diverse medical and health care systems, practices, and products that are not presently considered to be part of conventional medicine. ${ }^{1}$ Conventional medicine is medicine as practised by holders of recognized university degree(s) in Medical Science and by the allied health professionals, such as physical therapists, psychologists, and registered nurses. Synonyms of CAM include alternative medicine, complementary medicine, traditional medicine, and unconventional medicine. Traditional medicine includes not only medicinal substances of natural origin but also items like magic, charms, incantations, religious verses, spiritual methods, amulets, sacrifices, folklore customs, and even physical and mental tortures. Some health care providers practise both CAM and conventional medicine.
The earliest mention of traditional medicine is found in Rigveda, the oldest repository of knowledge in this subcontinent. Later ayurveda, developed from the Vedic concept of life, became the important source of all systems of medical sciences. In course of time, it became a part of culture and heritage of the people of the Indian Subcontinent.

CAM has maintained its popularity in all regions of the developing world and its use is rapidly spreading in industrialized countries. In China, traditional herbal preparations account for $30 \%-50 \%$ of the total medicinal consumption. In Europe, North America and other industrialized regions, over $50 \%$ of the population have used complementary or alternative medicine at least once. In Germany, 90\% of the population has used a natural remedy at some point in their life. The global market for herbal medicines currently stands at over US $\$ 60$ billion annually and is growing steadily. ${ }^{2}$

Address of Correspondence : Dr. A K M Monwarul Islam, Registrar, Department of Cardiology, National Institute of Cardiovascular Diseases, Sher-e-Bangla Nagar, Dhaka 1207, Bangladesh, E-mail: drmonwarbd@yahoo.com. 


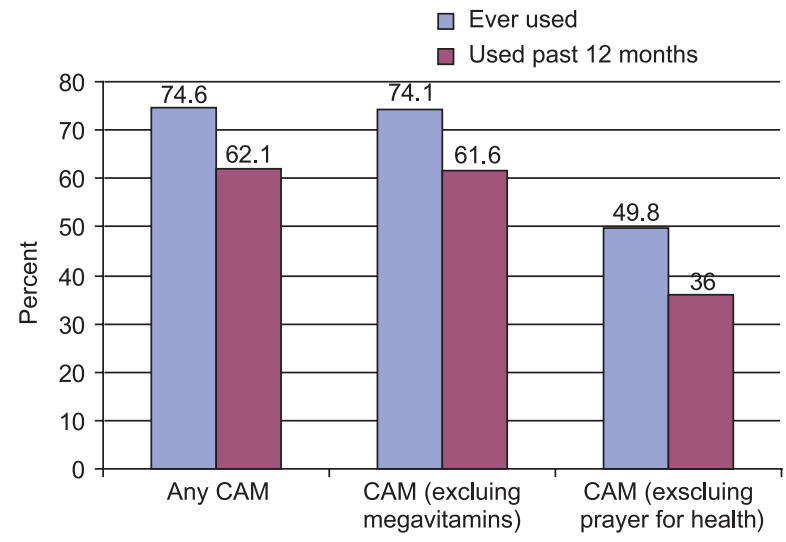

Fig.-1: Complementary and alternative medicine use by US adults. ${ }^{1}$

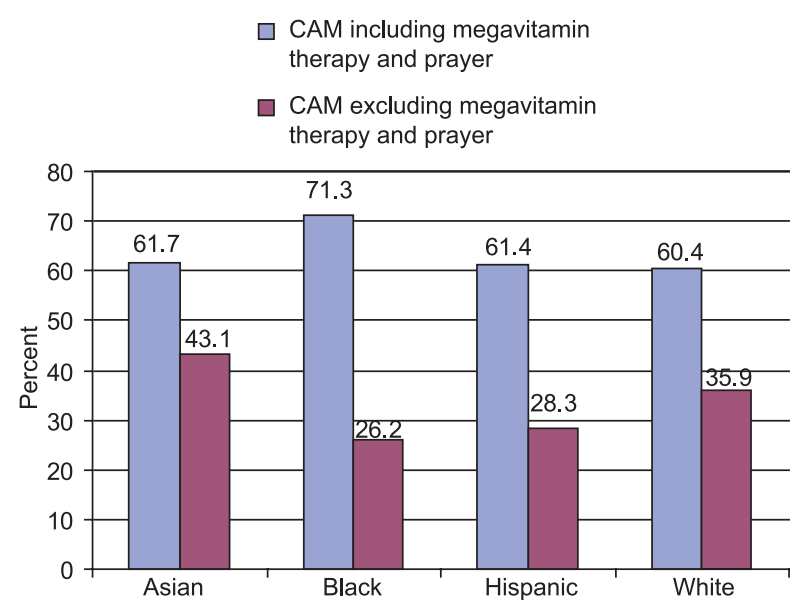

Fig.-2: Complementary and alternative medicine use by race/ethnicity in US. ${ }^{1}$

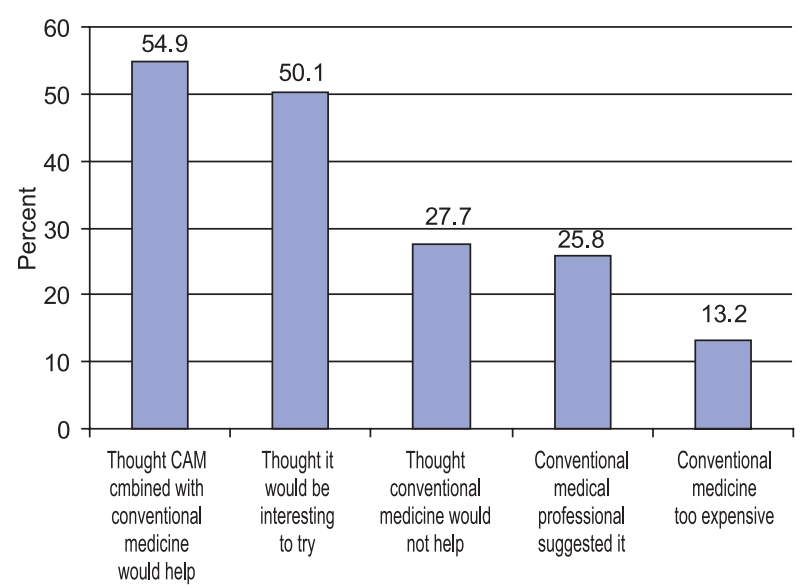

Fig.-3: Reasons for complementary and alternative medicine use by US adults. ${ }^{1}$

There is a growing body of evidence that certain complementary therapies are effective in certain clinical conditions. Scientific research is discovering the mechanism of some complementary therapies. However, the field is still poorly researched compared with conventional medicine. As with other areas of immature literature in medical practices, investigator bias, reporting bias, and publisher bias continue to impact the interpretation of the available data. ${ }^{3}$

Many people believe that products labeled "natural" are safe and good for them. But unregulated or inappropriate use of traditional medicines and practices can have negative or dangerous effects. For instance, in the United States, the herb "Ma huang" (Ephedra) was marketed as a dietary aid, whose over-dosage led to at least a dozen deaths, heart attacks and strokes. In Belgium, at least 70 people required renal transplant or dialysis for interstitial fibrosis of the kidney after taking a herbal preparation made from the wrong species of plant as slimming treatment. ${ }^{2}$

\section{Regulation of CAM:}

Regulation of CAM is less defined and less strict in comparison to that of conventional medicine. In the USA, Food and Drug Administration (FDA) does not directly regulate CAM. However, the National Center for Complementary and Alternative Medicine (NCCAM), a component of the National Institutes of Health (NIH), USA, is the Federal Government's agency for scientific research on CAM. ${ }^{1,4}$ Dietary supplements do not require standardization in the United States.

In the United Kingdom, all medicines are directly approved by the Medicines and Healthcare products Regulatory Agency (MHRA). Only those herbal remedies licensed in the UK, as well as, the traditional herbal medicines registered in the UK are regulated by the MHRA. Other herbal medicines are not assessed by the MHRA. ${ }^{6}$

In Bangladesh, substances claiming as drugs, whether allopathic, homeopathic, ayurvedic or unani, are regulated by the Directorate of Drug Administration, however, dietary supplements are out of their jurisdiction.

NCCAM of USA has five key treatment areas: A. Biologically based therapies, B. Manipulative and body-based methods, C. Energy therapies, D. Mindbody interventions, and E. Alternative medical systems. ${ }^{1}$ 


\section{A. Biologically Based Therapies: Botanicals and Dietary Supplements}

Biologically based practices in CAM use substances found in nature like botanicals, animal-derived extracts, vitamins, minerals, fatty acids, amino acids, proteins, prebiotics and probiotics, whole diets, and functional foods.

Biologically based practices in CAM use substances found in nature like botanicals, animal-derived extracts, vitamins, minerals, fatty acids, amino acids, proteins, prebiotics and probiotics, whole diets, and functional foods.

\section{Botanicals}

A botanical is a plant or plant part valued for its medicinal or therapeutic properties, flavor, and/or scent. Herbs are a subset of botanicals. Products made from botanicals that are used to maintain or improve health may be called herbal products, botanical products, or phytomedicines. A number of approved drug substances have their origin in plants, such as digoxin, atropine, reserpine, and amiodarone. Approximately 25 percent of pharmaceuticals prescribed today are derived from plant sources. Herbal products used for cardiovascular purposes include garlic, hawthorn, ginkgo, horse chestnut and arjun.

Garlic (Allium sativum) 1, 4, 5, 8-10

Garlic is used for prevention and treatment of atherosclerosis, hyperlipidemia, thrombosis, hypertension and diabetes.

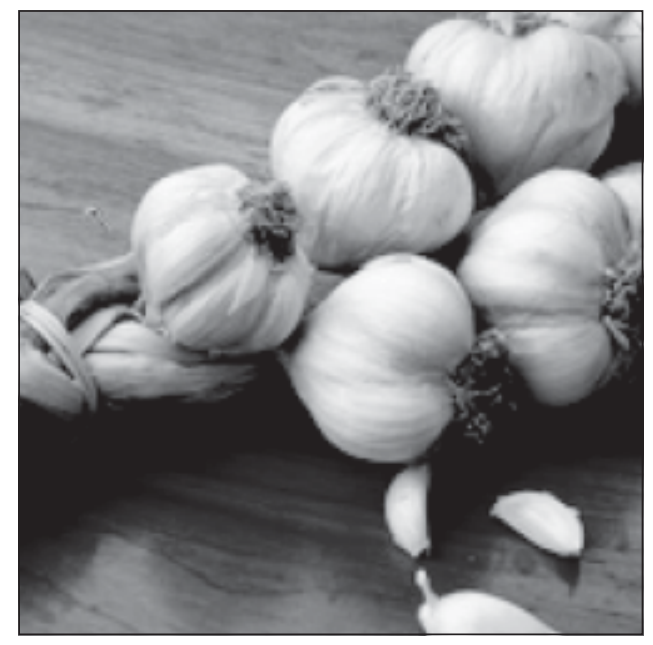

Fig.-4: Garlic $^{1}$
Allicin is the bioactive component responsible for the potential cardiovascular activity of garlic. The proposed mechanisms of action include decrease in cholesterol and fatty acid synthesis and cholesterol absorption, potent antioxidant properties, as well as, antiplatelet and fibrinolytic activity.

Clinical studies of garlic have yielded contradictory results. Short-term studies showed some beneficial effect on the lipid profile, whereas long-term studies of 6 months or more failed to demonstrate sustained benefit. Studies of garlic's effectiveness in hypertension have also suffered from poor methodology, and results have revealed small, mostly insignificant decreases in blood pressure. Evidence for the supplemental intake of garlic for both the primary and secondary prevention of heart disease is insufficient.

Side effects are occasional nausea, development of an unpleasant odor and increased risk of bleeding, specially in the perioperative period.

Hawthorn (Crataegus Species) 1, 4, 5, 11

Hawthorn species are a group of small trees and shrubs found throughout North America, Asia, and Europe. Cardiovascular indications include congestive cardiac failure, angina, and arrhythmias. Hawthorn's activity is related to the presence of flavonoids and procyanidins.

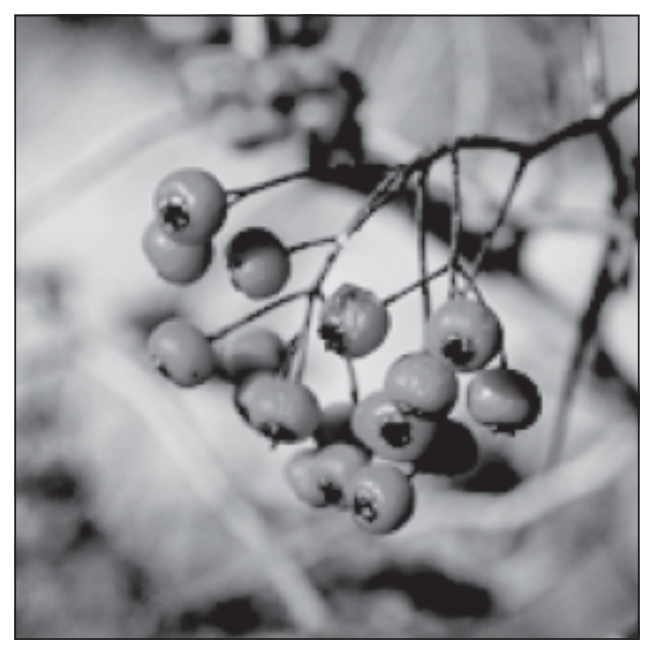

Fig.-5: Hawthorn ${ }^{1}$

Hawthorn has digitalis-like positive inotropic effects and is a peripheral vasodilator. It increases myocardial perfusion and stroke volume and reduces afterload. Several double-blind clinical studies in 
heart failure have shown objective improvement in cardiac performance using bicycle ergometry. In one study, hawthorn was found to be as effective as captopril in improving exercise tolerance. However, there are very limited data regarding its actual benefit in angina, and antiarrhythmia data are present only in animal studies.

Hawthorn may offer some advantages over digoxin in mild heart failure. Compared to digitalis, hawthorn has a wider therapeutic range, lower risk of toxicity, less arrhythmogenic potential, is safer to use in renal impairment, and can be safely used with diuretics and laxatives. However, care should be taken when combining it with beta-blockers and class III antiarrhythmics. In Germany, hawthorn can be prescribed for "mild cardiac insufficiency."

Side effects are rare but include gastrointestinal upset, sedation, dizziness, vertigo, headache, migraine, and palpitation.

Ginkgo biloba (Ginko-Leaf Extract) 1, 4, 5, 12 Ginkgo is found in China and Japan. Widely used for memory disorders and vertigo. Cardiovascular indication is for peripheral vascular disease. Flavonoids, terpenoids, and organic acids in ginko are probably responsible for its activity.

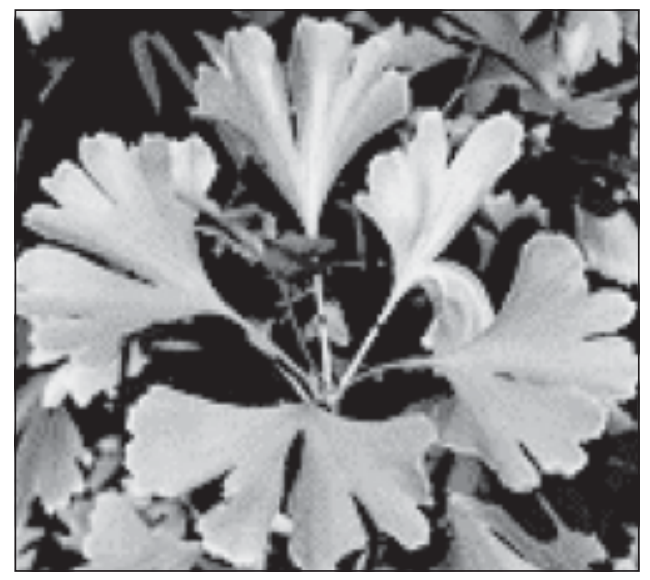

Fig.-6: Ginkgo bilobaital ${ }^{1}$

Ginkgo inhibits platelet activation factor, decreases blood viscosity, and reduces vascular resistance. It increases mean pain-free walking distance. However, ginko may increase risk of bleeding, so, it should not be co-administered with heparin, warfarin, clopidogrel and non-steroidal antiinflammatory drugs. It can increase blood pressure in patients taking thiazide diuretics. Side effects are common and include headache, dizziness, gastrointestinal complaints, and skin reaction.

\section{Horse Chestnut Tree Extract (Aesculus hippocastanum) $1,4,5,13,14$}

The horse chestnut tree is found worldwide and is used in chronic venous insufficiency.

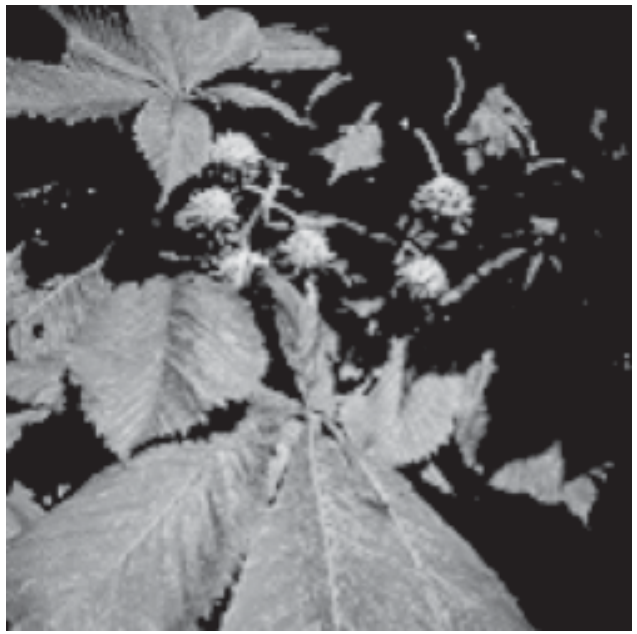

Fig.-7: Horse Chestnut Tree ${ }^{1}$

Its seeds contain aescin, a combination of triterpene and saponins, which causes sensitization to $\mathrm{Ca}^{2+}$ ions and exerts a sealing effect on small vessel permeability. Studies have reported the superiority of horse chestnut tree extract over placebo, with equal effectiveness to compression stockings.

Side effects are rare, including headache, itching, and dizziness. It may increase risk of bleeding probably due to its coumarin content. Also, it may cause hypoglycemia. The German Commission E has approved its use in chronic venous insufficiency.

\section{Policosanol $^{4,5,15}$}

Policosanol is a sugar cane extract. It contains a mixture of aliphatic alcohols. It is used in hyperlipidaemia. It inhibits cholesterol biosynthesis. It reduces total cholesterol by approximately 15 percent and LDL cholesterol by 20-30 percent. In a head-to-head comparison of $10 \mathrm{mg}$ of policosanol with $20 \mathrm{mg}$ of fluvastatin in women with elevated cholesterol, the lipid-lowering effects of policosanol were slightly superior to those of fluvastatin, and policosanol alone significantly inhibited the lipid peroxidation of $\mathrm{LDL}$. 
The most common side effects are weight loss, polyuria and headache. Policosanol can potentiate anticoagulant activity.

\section{Gugulipid, Guggulgum (Commiphora mukul) $)^{4,5,16,17}$}

Guggul, also called guggulipid, is an ethyl acetate extract of the gum resin of Commiphora mukul, a small bushy tree of India, Bangladesh, and Pakistan. It is used in hypercholestolemia, ischaemic heart disease and obesity. It inhibits cholesterol synthesis by blocking the farnesoid $\mathrm{X}$ receptor in liver cells. It may reduce total cholesterol and LDL$\mathrm{C}$ by 15 to 23 percent and triglyceride by 20 percent. Side effects include mild gastrointestinal symptoms and occasional hypersensitivity rash.

Red Rice Yeast (Monascus purpureus) ${ }^{4,5,18}$ Red yeast is the rice fermentation product of a mixture of several species of Monascus fungi, principally Monascus purpureas. It contains monacolin K (lovastatin, mevinolin) and other HMGCoA reductase inhibititors. It has been used to reduce blood cholesterol level. In a multicenter study of 187 subjects, red rice yeast lowered total cholesterol by 16.4 percent, LDL-C by 21.0 percent, triglycerides by 24.5 percent, and increased HDL-C by 14.6 percent.

Side effects of red rice yeast are gastrointestinal upset, headache, dizziness, hepatic impairment and rhabdomyolysis. Drug interactions may be with niacin, macrolides, cyclosporine, ketoconazole etc. Red yeast rice is now sold without lovastatin levels declared in the United States.

\section{Ginseng (Panax ginseng) 1, 38}

Asian ginseng is native to China and Korea. The root of ginseng contains ginsenosides or panaxosides that are thought to be responsible for the herb's medicinal properties.

It has been used for improving health and vigor, treating erectile dysfunction, hepatitis C, menopausal syndrome and diabetes. Cardiovascular indication is for hypertension. Studies on ginseng are not conclusive enough to prove its benefit. Most studies were small or had flaws in design and reporting.

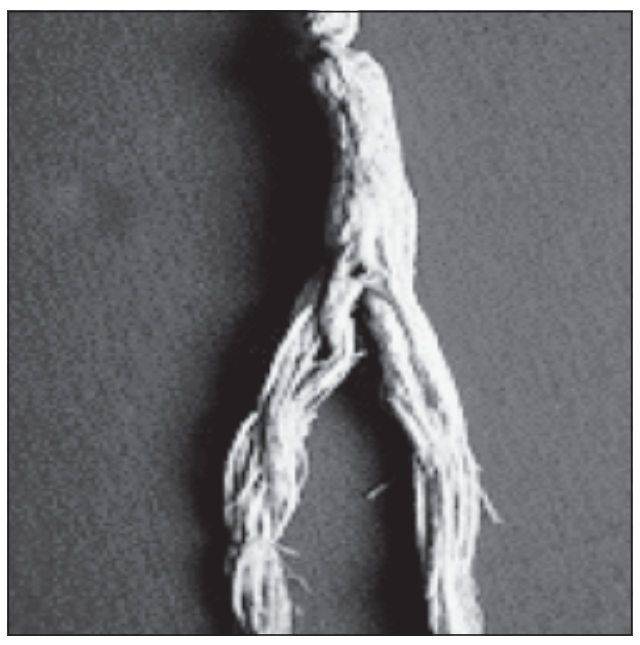

Fig.-8: Ginseng ${ }^{1}$

The most common side effects are headache, sleep disturbances, gastrointestinal problems and allergic reactions. There have been reports of breast tenderness, menstrual irregularities, hypoglycaemia and hypertension.

\section{Green Tea (Camellia sinensis) ${ }^{1}$}

Fresh leaves from the Camellia sinensis are steamed to produce green tea.

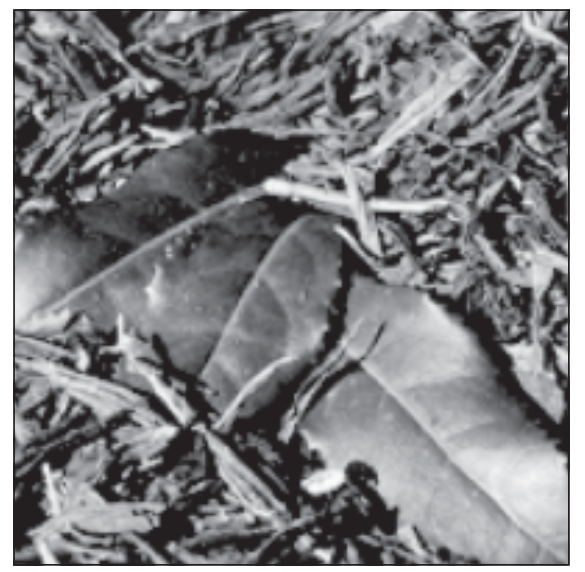

Fig.-9: Green Tea ${ }^{1}$

Cardiovascular use is to lower cholesterol levels. Green tea is thought to have beneficial effect on certain cancers, but studies have shown mixed results. Also, data on its role in weight loss, protection of the skin from sun damage and reduction of blood cholesterol are insufficient.

Green tea is safe in moderate amounts. However, its caffeine can cause insomnia, anxiety, nausea, diarrhea, urinary frequency, raised blood pressure, 
and in very high doses, seizure, delirium, or arrhythmia. It contains small amount of vitamin $\mathrm{K}$, which can make warfarin less effective.

Terminalia arjuna (Arjun) 19, 20,38,48

Arjun is found in India, Bangladesh, Sri Lanka, Burma and Mauritius. Ancient Indian physicians used its bark for "hritshool" (angina) and other cardiovascular conditions.

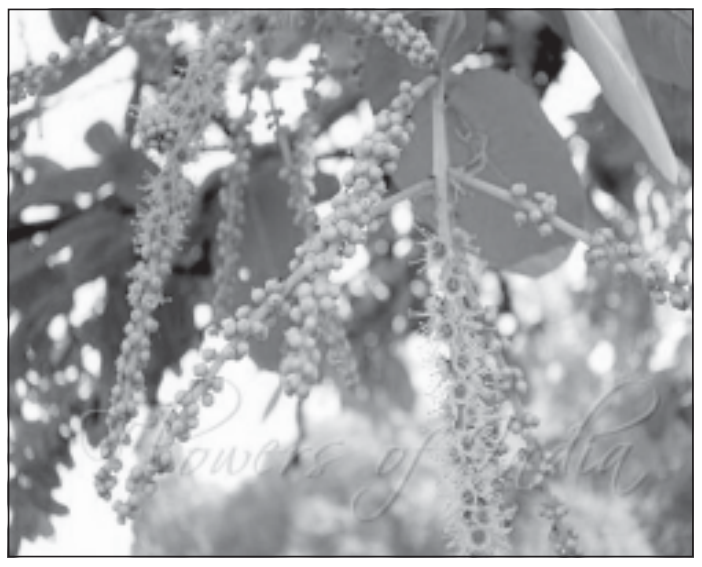

Fig.-10: Arjun $^{21}$

It contains glycosides, flavonoids, tannins and minerals. Flavonoids have antioxidant, antiinflammatory and lipid lowering effects while glycosides are cardiotonic. Its bark has been shown to exert significant inotropic and hypotensive effect, increase coronary blood flow and protect myocardium against ischemic damage. It also has mild diuretic, antithrombotic, prostaglandin $\mathrm{E}_{2}$ enhancing and hypolipidaemic activity. However, toxicological studies are lacking. One case of acute myocardial infarction was tentatively associated with use of arjun.

\section{Oleander (Nerium oleander/Thevetia peruviana) ${ }^{5}$}

A native of India and the Mediterranean, is widely used as a flowering plant. The oleander plant contains cardiac glycosides like oleandrin, oleandroside, nerioside, and digitoxigenin, which have positive inotropic and negative chronotropic actions.

It was once used for treating mild heart failure, but is now considered too dangerous for medicinal use. Oleander poisoning resembles digitalis toxicity which can be reversed by Fab fragments of anti-digoxin antibody. In view of the availability of digoxin, its use is not recommended.

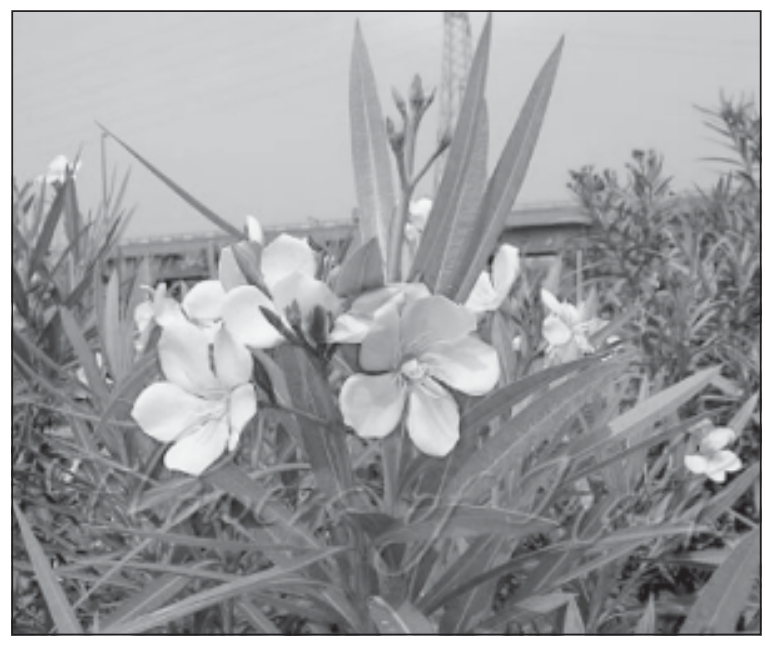

Fig.-11: Oleander (Nerium oleander) ${ }^{21}$

Ephedra (Ma huang) 1, 5, 38

Ephedra is a Chinese herbal medicine. It contains ephedrine. Ephedrine acts directly by stimulating alpha, beta-1, and beta- 2 adrenergic receptors, and indirectly by releasing endogenous norepinephrine. It is used to treat bronchospasm, asthma, bronchitis, allergic disorders, and nasal congestion, or as a central nervous system stimulant. The cardiovascular effects consist primarily of increased heart rate and peripheral vascular resistance.

Ephedrine has been associated with acute myocardial infarction (MI), severe hypertension and myocarditis, FDA banned the sale of ephedra-containing supplements in 2004 .

\section{Dietary Supplements}

In the Dietary Supplement Health and Education Act (DSHEA) of 1994, U.S. Congress defined a dietary supplement as a product taken by mouth that contains a "dietary ingredient" intended to supplement the diet. The "dietary ingredients" in these products may include vitamins, minerals, herbs or other botanicals, amino acids, enzymes, organ tissues, glandulars, and metabolites. ${ }^{1}$

In Bangladesh, dietary supplements are not regulated by the Directorate of Drug Administration, rather they are dealt with by the Bangladesh Standard Testing Institution (BSTI).

A number of dietary supplements have been postulated to have beneficial effects on cardiovascular disease. These include antioxidant vitamins, B vitamins, omega-3 fatty acids, plant sterols, soluble fiber, soy, nuts, alcohol, and teas. 
Omega-3 Fatty Acids 1, 4, 5, 22-25

Omega-3 polyunsaturated fatty acids have got plant and marine sources. The principal plant-based omega-3 fatty acids, alpha linolenic acid is found in soy, canola oil, flax seeds, and nuts. Omega-3 fatty acids derived from fish oil include docosahexaenoic acid and eicosapentaenoic acid.

The proposed mechanisms of cardiovascular benefit of omega-3 fatty acids include antiarrhythmic effect, triglyceride-lowering effect, mild hypotensive effect, inhibitory effect on platelets, anti-inflammatory effect and increased production of nitric oxide in vascular endothelium.

Cohort studies suggest a protective effect of fish or fish oil consumption on cardiovascular outcomes and slowed progression of atherosclerosis in native coronaries and vein grafts. The Gruppo Italiano per lo Studio della Sopravvivenza nell'Infarto Miocardico (GISSI)-Prevenzione study showed reduction in allcause mortality and sudden death in postmyocardial infarction patients. However the Diet and Angina Randomized Trial (DART)-2 actually demonstrated borderline excess mortality from high omega-3 intake. The apparent excess mortality appeared to be driven by fish oil capsules, not by oily fish consumption.

Currently, there are strong recommendations for consumption of fatty fish as part of a heart-healthy diet. In Europe, use of fish oil for secondary prevention after myocardial infarction is almost routinely practised. Nonetheless, the value of supplemental fish oil for primary or secondary prevention needs significant new studies to clarify current uncertainties.

\section{Antioxidants}

Antioxidants include vitamins like vitamin E, vitamin $\mathrm{C}$ and carotene, coenzyme $\mathrm{Q}$ and selenium. They are thought to have beneficial effect on cardiovascular outcomes. Epidemiological evidence suggests a favorable association between a diet high in antioxidants and reduced risk of coronary artery disease, but the clinical trials have failed to confirm the expected benefits.

\section{Vitamin $E^{4,5,26-29}$}

The Cambridge Heart Antioxidant Study (CHAOS) demonstrated reduction of combined end point of death or nonfatal MI by 47 percent by vitamin $\mathrm{E}$ given for secondary prevention. However, the Heart
Outcomes Prevention Evaluation (HOPE) trial, the GISSI-Prevenzione trial and the collaborative group of the Primary Prevention Project (PPP) found no therapeutic benefit of vitamin E. In the HOPE-The Ongoing Outcomes (TOO) trial there was actually a modest increase in heart failure with active treatment. The Women's Heath Study found mortality benefit of vitamin E, but no effect of it on total cardiovascular events, myocardial infarction or stroke. At present, the preponderance of the evidence does not support a role for vitamin $\mathrm{E}$ supplements in prevention of coronary artery disease.

Vitamin C (Ascorbic acid) 4 , 5, 28, 29

Most observational and cohort studies do not find any relationship between vitamin $\mathrm{C}$ intake and cardiovascular disease. However, the Nurses' Health Study, showed decreased risk of coronary artery disease with vitamin $\mathrm{C}$ intake.

Beta carotene 4,5

Trials showed no cardiovascular benefit, rather there was increased incidence of lung cancer and hemorrhagic stroke mortality in the AlphaTocopherol, Beta Carotene Cancer Prevention study.

Combination Antioxidant Vitamins 4, 5, 26-29

In the Heart Protection Study, combination of vitamin $\mathrm{E}$, vitamin $\mathrm{C}$, and beta-carotene regimen was found to be safe, but of no therapeutic benefit. On the other hand, the Antioxidant Supplementation in Atherosclerosis Prevention (ASAP) study demonstrated significant slowing of carotid atherosclerosis with supplementation of vitamin $\mathrm{E}$ and vitamin C. Antioxidants are widely available nowa-days. But supplementation of antioxidant vitamins and selenium to prevent cardiovascular disease is not recommended. Rather, AHA Diet and Lifestyle Recommendation 2006, encourages consumption of antioxidants from food only.

\section{B Vitamins $4,5,30$}

Homocysteine, an important cardiovascular risk factor, can be decreased in blood by the administration of supplemental folate, with or without vitamins $\mathrm{B}_{6}$ and $\mathrm{B}_{12}$. Epidemiologic studies were suggestive of potential cardiovascular benefit with B-vitamin supplementation. But most trials failed to show such effect. A meta-analysis of four randomized, controlled trials found no evidence of slowing of atherosclerosis by B vitamin supplementation. In one study, there was, rather, 
increased risk of restenosis and revascularization after coronary stenting.

\section{Coenzyme Q10 (Ubiquinone) ${ }^{29}$}

Coenzyme Q10 belongs to a family of substances called ubiquinones. Ubiquinones are fat-soluble vitamin-like substances involved in electron transport and energy production in mitochondria. It also functions as an antioxidant. Primary dietary sources include oily fish, organ meats such as liver, and whole grains. Cardiovascular uses of Coenzyme Q10 are in congestive cardiac failure and cardiomyopathy. However, the value of its supplementation in patients with cardiovascular disease is still uncertain.

\section{Chelation Therapy ${ }^{4,5}$}

The intravenous infusion of ethylenediaminetetraacetic acid (EDTA) is used in atherosclerotic vascular disease for removal of calcium from atheromatous plaques. The Program to Assess Alternative Treatment Strategies to Achieve Cardiac Health (PATCH) study found no such benefit.

\section{Soluble Fiber ${ }^{4,5}$}

Dietary fibers are the indigestible portion of plant foods. Examples include cellulose, dextrin, inulin, lignin, pectin, chitin, wax, beta-glucan and oligosaccharides. They may be insoluble or soluble. The soluble fibers are the edible parts of plants or similar carbohydrates resistant to digestion and absorption in the human small intestine with complete or partial fermentation in the large intestine. Soluble fiber is found in all plant foods, including legumes (pea, soybean, and other beans), vegetables (carrot, potato and onion), fruits (plums, berries, prune juice), oat, barley and psyllium seed husk. Dietary fiber supplements reduce LDLcholesterol and blood sugar levels. Epidemiologic findings suggest a possible impact on coronary artery disease and outcome.

\section{Soy Protein and Isoflavones (Phytoestrogens) ${ }^{4,5,31}$}

Soy (Glycine max) is a plant of the pea family. Soybean is the high-protein seed of the soy plant. It contains isoflavones-compounds similar to the female hormone estrogen. Soy supplements may contain isoflavones or soy protein or both. Soybeans can be cooked and eaten or used to make tofu, soy milk, and other foods including baked foods.

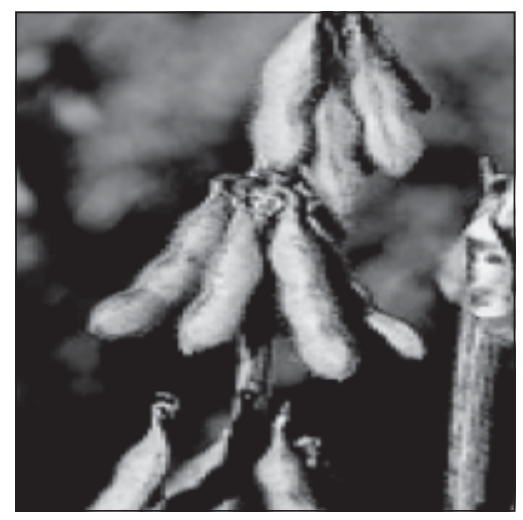

Fig.-12: Soy (Glycine $\max )^{1}$

Soy products are used in hypercholesterolemia, hypertension, menopausal syndrome, osteoporosis, dementia, as well as, in breast and prostate cancer. Substitution of soy protein for animal protein causes small reduction of LDL-cholesterol, triglycerides and blood pressure. Soy isoflavones were tested in 19 studies and had no effects on lipids or blood pressure. So use of isoflavone supplements in food or pills is not recommended.

\section{Plant Sterols and Stanols 4, 5, 32}

Plant sterols and stanols are phytosterols that resemble the chemical structure of animal cholesterol. They are present in fruits, vegetables, nuts, seeds, cereals, legumes and vegetable oils. Sitosterol, campesterol and stigmasterol are the most common phytosterols. Plant sterols when saturated, form stanols e.g. sitostanol and campestanol. Phytosterols when incorporated into foods inhibit cholesterol absorption in intestine. They have been shown to lower blood cholesterol level. Introduction of plant sterols into the food supply e.g., by fortification of margarines and food oils, might lower coronary heart disease risk for the whole population. However, more information is required before their routine ingestion is recommended.

\section{Alcohol 4, 5, 33}

Mild to moderate alcohol consumption has been associated with reduction in stroke and rates of MI, improvement of claudication, and improved cardiovascular survival. Alcohol intake from any type of alcoholic beverage appears to be beneficial, but some studies suggest that red wine confers additional health benefits. The red hue of red wine is contributed by the grapes used for its production. The regular drinking of red wine has been suggested as the 
explanation for the "French paradox", the relatively low incidence of coronary atherosclerosis in France as compared with other Western countries, despite the generally high intake of saturated fat in the French diet. The polyphenolic compounds in red wine, such as flavonoids and resveratrol, may limit the start and progression of atherosclerosis. However, excessive alhocol intake may cause numerous adverse effects including cardiomyopathy.

\section{L-Carnitine $^{5,8}$}

Carnitine transports long-chain fatty acids into the mitochondria. It is concentrated in tissues like skeletal and cardiac muscle that utilize fatty acids as a dietary fuel. It is often promoted as an aid for weight loss, to improve exercise performance, and to enhance a sense of well-being. Studies have examined supplemental carnitine in the management of cardiac ischemia and peripheral arterial disease. At present it is unclear whether Lcarnitine provides any benefit beyond wellestablished therapies. Carnitine supplements may cause nausea, vomiting, abdominal cramps, diarrhea, and a "fishy" body odor. It may potentiate warfarin's anticoagulant activity.

Summary of recommendations for Biologically Based Therapies ${ }^{5}$

Supplements/interventions that can be recommended:

1. Omega-3 supplements 1 to $2 \mathrm{~g}$ per day if insufficient omega-3 intake from fish

2. Stanol/sterol ester margarines (2 g per day)

3. Soluble fiber (5 to $20 \mathrm{~g}$ per day)

4. Soy foods and soy protein (equivalent to $25 \mathrm{~g}$ soy protein daily)

Possibly useful for indications noted:

1. Moderate alcohol intake for cardiovascular risk reduction $\left(1 /{ }_{2}\right.$ to 2 drinks per day - a drink is 5 oz of wine, $12 \mathrm{oz}$ of beer or $1.5 \mathrm{oz}$ of 80 proof whiskey)

2. Tea (1 to 2 cups daily) for cardiovascular risk reduction

3. Recommended dietary intake of magnesium

4. Folic acid supplementation (plus vitamins $B_{6}$ and $\mathrm{B}_{12}$ ) if homocysteine is elevated.
Cannot be recommended (however, probably not harmful):

1. Folic acid supplementation for vascular disease if homocysteine is not elevated

2. Garlic for lipid lowering

3. Soy isoflavones for lipid lowering

4. L-arginine supplementation for nutritional support

5. Coenzyme Q10 for nutritional support

6. Hawthorn for mild heart failure

7. Ginkgo biloba for peripheral vascular disease

8. Horse chestnut seed extract for peripheral vascular disease

Supplements/interventions not recommended (possibly harmful):

1. Vitamins $\mathrm{C}>2,000 \mathrm{mg} /$ day and $\mathrm{E}>1,000 \mathrm{mg} /$ day; beta-carotene not recommended

2. Ephedra, oleander, and other herbs/botanicals with well-defined contraindications.

B. Manipulative and Body-Based Methods $\mathbf{s}^{1,4,5,50}$ Acupuncture, acupressure, and massage techniques represent manipulative and body-based therapies. Worldwide, more than 40 percent of physicians recommend acupuncture to their patients.

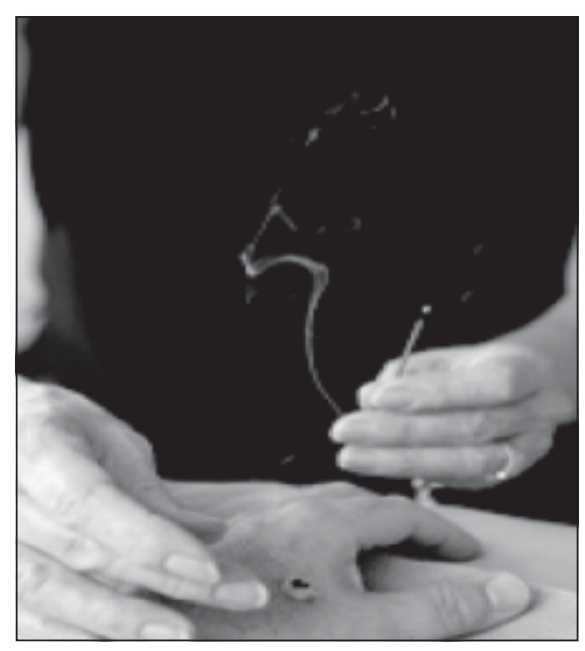

Fig.-13: Acupuncture ${ }^{1}$

In cardiovascular care, acupuncture has been used for angina, hypertension, and arrhythmias. It may be effective to some extent probably due to its ability to inhibit autonomic sympathetic outflow and to release endogenous opioids. 


\section{Energy Therapies 1, 4, 5, 51}

Energy therapies or bioenergetics involve use of energy fields to influence physiologic, emotional, and spiritual healing. Qi gong, healing touch and Reiki are the examples. No scientific evidence has demonstrated or characterized actual bioenergy fields associated with many of these techniques, although practitioners claim to see, feel, or otherwise sense the color, alignment, intensity, and flow of such energy in practice. In cardiovascular application, qi gong has been claimed to influence hypertension, sudden death, hospitalization after myocardial infarction and mortality with stroke. Yoga has been associated with improved heart rate variability and respiratory variables. The reproducibility of these findings has not been established. According to an expert consensus document on complementary and integrative medicine by the American College of Cardiology Foundation, conditions for which bioenergy therapies are not contraindicated (but not specifically recommended) include: 1 . If a bioenergy treatment does not interfere with standard, accepted, and proven therapy, 2. If standard therapies do not provide optimal symptomatic improvement, or for a condition that is potentially functional or has functional overlay. No bioenergy therapy should be considered a substitute for standard, accepted, and approved therapies.

\section{Mind-Body Interventions 1, 4, 5, 51}

Mind-body medicine typically focuses on intervention strategies that are thought to promote health, such as relaxation, hypnosis, visual imagery, meditation, yoga, biofeedback, tai chi, qi gong, cognitivebehavioral therapies, group support, autogenic training, and spirituality. The field views illness as an opportunity for personal growth and transformation and health care providers as catalysts and guides in this process. Mind-body interventions constitute a major portion of the overall use of CAM by the public. In 2002, mindbody techniques, including relaxation techniques, meditation, guided imagery, biofeedback, and hypnosis, were used by about 17 percent of the adult U.S. population. Prayer was used by 45 percent of the population for health reasons. Literatures provide evidence that stress, emotional states and spiritual attitudes have significant correlations to cardiovascular outcomes such as hypertension, MI, stroke, and cardiac death. The actual ability of mind- body or mind-body-spirit therapies to benefit the natural history of cardiovascular disease, however, remains unclear.

\section{E. Alternative Medical Systems ${ }^{1,4,5,50}$}

Alternative medical systems include diagnostic and therapeutic applications that are based on paradigms conceptually distinct from the allopathic structure of modern medical practices. They are culturally based and in many cases ancient in their history. In homeopathy, a key premise is that every person has energy called a vital force or self-healing response. When this energy is disrupted, health problems develop. Homeopathy aims to stimulate the body's own healing responses. Homeopathic treatment involves giving extremely small doses of substances that produce characteristic symptoms of illness in healthy people when given in larger doses. This approach is called "like cures like". Research studies on homeopathy have been contradictory in their findings. Some analyses have concluded that there is no strong evidence supporting homeopathy as effective for any clinical condition. However, others have found positive effects from homeopathy. A meta analysis of homeopathic treatments of more than 80 studies indicated, compared to placebo, that homeopathic treatments might be effective. The positive effects are not readily explained in scientific terms. There is a point of view that homeopathy does work, but that modern scientific methods have not yet explained why. The homeopathic remedies need not go through the testing and review by the FDA for safety and effectiveness before they can be sold. The modality is considered to be safe. The FDA reviewed the few reports of illness associated with the use of homeopathic remedies and decided that the remedies were not likely to be the cause, because of the high dilutions.

In traditional Chinese medicine, cardiovascular disorders are simply one feature of symptom complexes characterized across four relative states of yin deficiency or excess combined with yang deficiency or excess. In ayurvedic medical systems, the body is essentially referenced across five inorganic elements: earth, water, fire, air, and ether. The body itself is envisioned as coarse material, or maya, that is structurally configured by vibrational energy conveyed from a collective or cosmic source, or Atma. 
Although alternative medical systems at first blush can seem radical in their departure from the Western scientific medical model, current directions in wellness-oriented lifestyle modification strategies for prevention of cardiovascular disease represent a movement with a distinctively holistic character in the mainstream of modern practice.

\section{CAM in Bangladesh ${ }^{53,54}$}

Traditional medicine plays a very important role in Bangladesh, particularly at the primary health care level. An estimated 70 to $75 \%$ people of the country still use traditional medicine for management of their health problems. The homeopathic, ayurvedic and unani systems of traditional health care have firm roots in Bangladesh and are widely practised all over the country. They are now officially recognized in Bangladesh. They are practised side by side with modern allopathic medicine as an alternative and supplementary system of medicine. There are about two dozens of registered herbal pharmaceuticals in Bangladesh. Of which about four big pharmaceuticals (Sadhana, Sakhti, Kundeswari and Hamdard) are now producing more than 80 percent of the traditional remedies. Recently, several reputed pharmaceutical companies manufacturing allopathic medicine have started producing herbal products and dietary supplements. Out of about 2000 medicinal herbs included in the Materia Medica of traditional medicine in this subcontinent 450 to 500 have so far been enlisted as growing or available in Bangladesh. A rapidly increasing number of CAM products (e.g. omega-3 fatty acids, bee pollen, evening primrose oil, metatonine, slimming tea, yohimbine) are being imported in Bangladesh.

\section{Conclusion}

Throughout the world, CAM therapies are being used increasingly, despite their inadequate scientific bases. They are neither totally ineffective, nor harmless. New information is becoming available by scientific research. Day by day, they are gaining more and more institutional, regional and global recognition as well. Right now, CAM therapeutics is probably best considered as adjuncts to current standard medical care. Systematic research to uncover mechanisms of action and better profile the actual safety and efficacy of CAM therapies should be given due priority. Physicians including cardiologists must have appropriate knowledge about these therapies to survive in this world of therapeutic jargons and to guide people in the right way.

\section{Conflict of Interest - None.}

\section{References:}

1. National Institutes of Health. National Center for Complementary and Alternative Medicine (NCCAM). Available at: http: //nccam.nih.gov.

2. World Health Organization. Traditional medicine. Available at: http//www.who.int.

3. Zollman C, Vickers A. ABC of complementary medicine. What is complementary medicine? BMJ. 1999; 319: 693696.

4. Krucoff MW, Liebowitz R, Vogel JHK, Mark D. Complementary and alternative medical therapy in cardiovascular care. In: Fuster V, Alexander RW, O'Rourke RA, eds. Hurst's The Heart. vol 2. New York: McGraw-Hill, 2008.

5. Vogel JHK, Bolling SF, Costello RB, et al. Integrating complementary medicine into cardiovascular medicine: a report of the American College of Cardiology Foundation Task Force on Clinical Expert Consensus Documents (Writing Committee to Develop an Expert Consensus Document on Complementary and Integrative Medicine). J Am Coll Cardiol. 2005; 46: 184-221.

6. Ferner RE, Beard K. Regulating herbal medicines in the UK. A specific committee could help to distinguish unproved herbal therapies from rational treatments. [Editorial]. BMJ. 2005; 331; 62-63.

7. Lichtenstein AH, Appel LJ, Brands M, Carnethon M, Daniels S, Franch HA, Franklin B, Kris-Etherton P Harris WS, Howard B, Karanja N, Lefevre M, Rudel L, Sacks F, Horn LV Winston M \& Wylie-Rosett J. Summary of American Heart Association Diet and Lifestyle Recommendation Revision 2006. Arterioscler. Thromb. Vasc. Biol. 2006; 26: 2186-2191.

8. National Institutes of Health. Office of Dietary Supplements. Available at: http: //www.ods.od.nih.gov.

9. Mulrow C, Lawrence V, Ackerman R, et al. Garlic: Effects on Cardiovascular Risks and Disease, Protective Effects against Cancer, and Clinical Adverse Effects. Rockville, MD: Agency for Healthcare Research and Quality; 2000. AHRQ publication 01-E023.

10. Silagy CA, Neil HA. A meta-analysis of the effect of garlic on blood pressure J Hypertens. 1994; 12(4): 463468.

11. Tauchert M. Efficacy and safety of Crataegus extract WS 1442 in comparison with placebo in patients with chronic stable New York Heart Association class III heart failure. Am Heart J. 2002; 143(5): 910-915.

12. Pittler MH, Ernst E. Ginkgo biloba extract for the treatment of intermittent claudication: a meta-analysis of randomized trials. Am J Med. 2000; 108: 276-281.

13. Sirtori, CR. Aescin: pharmacology, pharmacokinetics and therapeutic profile. Pharm Res. 2001; 44(3): 183-193. 
14. Pittler MH, Ernst E. Horse chestnut seed extract for chronic venous insufficiency. Cochrane Database Syst Rev. 2006; 1: CD003230.

15. Mas R. Policosanol. Drugs Future. 2000; 25: 569-586.

16. Nityanand S, Srivastava JS, Asthana OP. Clinical trials with gugulipid. A new hypolipidaemic agent. $J$ Assoc Physicians India. 1989; 37: 323-328.

17. Szapary PO, Wolfe ML, Bloedon LT, et al. Guggulipid for the treatment of hypercholesterolemia: a randomized control trial. JAMA. 2003; 290: 765-772.

18. Heber D, Yip I, Ashley JM, et al. Cholesterol-lowering effects of a proprietary Chinese red yeast rice dietary supplement. Am J Clin Nutr. 1999; 69: 231-236.

19. Dwivedi S. Terminalia arjuna Wight \& Arn.- A useful drug of cardiovascular disorders. Journal of Ethnopharmacology. 2007; 114-129.

20. Bharani A, Ganguli A, Bhargava KD. Salutary effect of Terminalia arjuna in patients with severe refractory heart failure. Int $J$ Cardiol. 1995; 49: 191-199.

21. Flowers of India: Medicinal plants. Available at: http// www.flowersinindia.net.

22. Kris-Etherton PM, Harris WS, Appel LJ. American Heart Association. Nutrition Committee. Fish consumption, fish oil, omega-3 fatty acids, and cardiovascular disease. Circulation. 2002; 106: 2747-2757.

23. Undeland I, Ellegard L, Sandberg A. Fish and cardiovascular health. Scand J Nutr. 2004; 48 (3): 119130

24. Hooper L, Thompson RL, Harrison RA, et al. Risks and benefits of omega 3 fats for mortality, cardiovascular disease, and cancer: systematic review. BMJ. 2006; 332: 752-760.

25. Brouwer IA, Zock PL, Camm AJ, et al. Effect of fish oil on ventricular tachyarrhythmia and death in patients with implantable cardioverter defibrillators: the SOFA randomized trial. JAMA. 2006; 295: 2613-2619.

26. Kris-Etherton PM, Lichtenstein AH, Howard BV, Steinberg D, Witztum JL. Antioxidant Vitamin Supplements and Cardiovascular Disease. American Heart Association Council on Nutrition, Physical Activity, and Metabolism. Nutrition Committee. Circulation. 2004; 110; 637-641.

27. HOPE and HOPE-TOO Trial Investigators. Effects of long-term vitamin E supplementation on cardiovascular events and cancer: a randomized controlled trial. JAMA. 2005; 293: 1338-1347.

28. Salonen RM, Nyyssonen K, Kaikkonen J, et al. Sixyear effect of combined vitamin $\mathrm{C}$ and $\mathrm{E}$ supplementation on atherosclerotic progression: the Antioxidant Supplementation in Atherosclerosis Prevention (ASAP) study. Circulation. 2003; 107: 947953.

29. Agency for Healthcare Research and Quality. U.S. Department of Health and Human Services. Effect of Supplemental Antioxidants Vitamin C, Vitamin E, and
Coenzyme Q10 for the Prevention and Treatment of Cardiovascular Disease. AHRQ Publication No. 03E043. Available at: http// www.ahrq.gov.

30. Lange H, Suryapranata H, De Luca G, et al. Folate therapy and in-stent restenosis after coronary stenting. $N$ Engl J Med. 2004; 350: 2673-2681.

31. Sacks FM, Lichtenstein A, Van Horn L, et al. Soy protein, isoflavones, and cardiovascular health: an AHA Science Advisory for professionals from the Nutrition Committee. Circulation. 2006; 113: 1034-1344.

32. Lichtenstein AH, Deckelbaum RJ. AHA Science Advisory: Stanol/Sterol Ester-Containing Foods and Blood Cholesterol Levels: A Statement for Healthcare Professionals from the Nutrition Committee of the Council on Nutrition, Physical Activity, and Metabolism of the American Heart Association. Circulation. 2001; 103: $1177-1179$.

33. Goldberg IJ, Mosca L, Piano MR, Fisher EA. AHA Science Advisory: Wine and your heart: a science advisory for healthcare professionals from the Nutrition Committee, Council on Epidemiology and Prevention, and Council on Cardiovascular Nursing of the American Heart Association. Circulation. 2001; 103: 472-475.

34. Stanner S. ed. Cardiovascular Disease: Diet, Nutrition and Emerging Risk Factors. The Report of a British National Foundation Task Force. Oxford: Blackwell Publishing, 2005.

35. Hulisz DT. Top herbal products: Efficacy and safety concerns. Available at: http//www.medscape.com.

36. Valli G, Giardina EG. Benefits, adverse effects and drug interactions of herbal therapies with cardiovascular effects. J Am Coll Cardiol. 2002; 39: 1085-1095.

37. Manheimer E, Berman B, Dubnik H, Beckner W. Cochrane reviews of complementary and alternative therapies: evaluating the strength of evidence. Available at: http//www.cochrane.org.

38. Tracy TS, Kingston RL, eds. Herbal Products, Toxicology and Clinical Pharmacology. $2^{\text {nd }}$ ed. New Jersey: Humana Press; 2007.

39. Izzo AA, Di Carlo G, Borrelli F, Ernst E. Cardiovascular pharmacology and herbal medicines: the risk of drug interaction. Int J Cardiol. 2006; 110(1): 93.

40. Arthur H, Patterson C, Stone J. The role of complementary and alternative therapies in cardiac rehabilitation: a systematic evaluation. Eur $J$ Cardiovasc Prev Rehabil. 2006; 13(1): 3-9.

41. Lin MC, Nahin R, Gershwin M, et al. State of complementary and alternative medicine in cardiovascular, lung, and blood research: executive summary of a workshop. Circulation. 2001; 103(16): 2038-2041.

42. Hu Z, Yang X, Ho PC, Chan SY, Heng PW, Chan E, Duan W, Koh HL, Zhou S. Herb-drug interactions: a literature review. Drugs. 2000; 65(9): 1239-1282.

43. World Health Organization. Guidelines for the regulation of herbal medicines in the South-East Asia Region. 2004. Available at: http: //www.who.int/ publications/en. 
44. World Health Organization. WHO Traditional Medicine Strategy 2002-2005. 2002 Available at: http: // www.who.int/publications/en.

45. Jonas W, Levin J, eds. Essentials of Complementary and Alternative Medicine. Philadelphia: Lippincott, Williams \& Wilkins; 1999.

46. Diamond WJ. The Clinical Practice of Complementary, Alternative, and Western Medicine. Florida: CRC Press; 2001.

47. Schulz V, Hansel R, Tyler VE. Rational phytotherapy: A Physician's Guide to Herbal Medicine. 4th ed. Berlin: Springer-Verlag; 2001.

48. James A. Duke JA, Bogenschutz-Godwin MJ, duCellier J, Duke PK. Handbook of Medicinal Herbs. $2^{\text {nd }}$ ed. Florida: CRC Press, 2002.

49. De Smet PA. Herbal remedies. N Engl J Med. 2002; 347(25): 2046-2056.
50. Lao L. Traditional Chinese medicine. In: Jonas W, Levin J, eds. Essentials of Complementary and Alternative Medicine. Philadelphia: Lippincott, Williams \& Wilkins; 1999.

51. Jonas WB, Crawford CC. Science and spiritual healing: a critical review of spiritual healing, "energy" medicine and intentionality. Alt Ther Health Med. 2003; 9(2): 5661.

52. Islam MS. Therapeutic drug use in Bangladesh: policy versus practice. Indian J Med Ethics. 2008; V(1); 24-25.

53. Shaheen R, Rahman MS. Unani and Ayurvedic Medicine in Bangladesh: Cognition of Health Care Seekers at a Public Hospital. J Health Manag. 2002; 4: 39-52.

54. Banglapedia. Traditional Medicine. Available at: http// www.banglapedia.org. 